\title{
Research on the Way to Improve the Service Quality of Shanxi Government WeChat
}

\author{
Zhen Feng ${ }^{1,2, a,{ }^{*} \text {, Liying Zhang }}{ }^{2, b}$, Tianli Shen ${ }^{2, c}$ \\ ${ }^{1}$ Cooperative Innovation Center for Transition of Resource-based Economics \\ ${ }^{2}$ School of Management Science and Engineering, Shanxi University of Finance and Economics, Taiyuan, \\ China \\ afengzhen4@126.com, b617524651@qq.com, '870107462@qq.com \\ *Corresponding author
}

Keywords: User Demands, the Service Quality of Government WeChat, Analytical KANO Theory.

\begin{abstract}
Based on the user demands, the service quality attributes of government WeChat were constructed. The service quality of Shanxi government WeChat were analyzed using the analytical KANO theory of government WeChat, and the way to improve the service quality of Shanxi government WeChat was proposed. "No need to care" includes sound news, online event registration, etc.; "Surplus Satisfaction" does not have the service quality attributes of government WeChat; "Maintain performance" includes timely release of news, rich content of government affairs information and humor of news language, etc.; "Key enhancement" includes providing inquiry functions, collection channels of public suggestions, etc.. The conclusion provides reference for improving the service quality of government WeChat in Shanxi.
\end{abstract}

\section{Introduction}

General Secretary $\mathrm{Xi}$ repeatedly mentioned the Internet in the report of the 19th National Congress of the Party in 2017. Currently, the new media has increasingly become an important channel in the openness of government affairs. As of December 2017, the number of users of online government services in China reached 485 million, accounting for $62.9 \%$ of the total netizens. Among them, the utilization rate of government services through the government WeChat was 23.1\%, up 7.4 percentage points from the end of 2016 [1]. Since August 30, 2012, the government WeChat has developed rapidly and achieved great success. However, there is a significant imbalance in regional development up to now. According to the comprehensive ranking of provincial new media for government affairs, the top three are Shanghai, Zhejiang, Beijing, while Shanxi Province ranks the bottom in terms of service performance, with all indexes lower than the above areas [2]. Therefore, it is an urgent problem to pay attention to the way to improve the service quality of government WeChat in Shanxi.

\section{Analytical KANO Theory}

In an effort to address the inherent deficiencies of traditional KANO theory, $\mathrm{Q} \mathrm{Xu}$, et. al. put forward an analytical KANO theory, which refers to introducing the KANO indices, KANO classifiers, configuration index and KANO evaluator into the traditional KANO theory [3]. Based on this idea, this paper defines the service quality attribute of government WeChat: five types of service quality attributes are determined: (1)"A" means attractive quality attributes, which are unexpected to the user and can result in great satisfaction if they are available, (2)" $M$ " means must-be quality attributes, which are expected by the user and they lead to extreme dissatisfaction if they are absent or poorly satisfied, (3)"O" means one-dimensional quality attributes, which reflect the better fulfillment leads to linear increment of user satisfaction, (4)"I" means indifference quality attributes, which are those that the user is not interested in the service level of government WeChat, and (5)"R" means reverse quality attributes, which means the better the service of government 
WeChat, the more dissatisfied the users are.

\section{The Questionnaire Design of KANO about the Government WeChat of Shanxi Province}

According to the analytic KANO theory, this paper designs the questionnaire of KANO about the government WeChat of Shanxi Province, which is shown in Table 1. The indicators in the questionnaire come from the investigation.

This questionnaire is divided into two parts: the first part is the information related to users' characteristics in Shanxi, including users' gender, age and education and so on; the second part is the survey about the service quality of government WeChat, which is the main part of the questionnaire. Based on the analysis of news communication, service function and user interaction; the corresponding questions were designed in Table 1. In the questionnaire, the feelings of users for each question were divided into five levels: "dislike", "live with", "neutral", "must-be" and "like""[4].

The questionnaire was distributed online in Shanxi. A total of 560 questionnaires were distributed from July 10, 2017 to December 13, 2017.

Table 1 The service quality attributes of government WeChat

\begin{tabular}{lll}
\hline $\begin{array}{l}\text { Serial } \\
\text { number }\end{array}$ & Attributes of service quality & Services for users \\
\hline$f_{9}$ & Timely release of news & \\
$f_{10}$ & Rich content of government affairs information & \\
$f_{11}$ & Local social news & Communication (Time, Content, \\
$f_{12}$ & Various ways of information transmission & Method, Language, Frequency, \\
$f_{13}$ & Sound news & etc.) \\
$f_{14}$ & Popular policy interpretation & \\
$f_{15}$ & Humor of news language & \\
$f_{16}$ & News language with local characteristics & \\
$f_{17}$ & Number of news pushed each time & Services (Appointment to do \\
\hline$f_{18}$ & Online appointment to do things & things, Payments, Query function, \\
$f_{19}$ & Online payments (utilities, insurance, etc.) & Poll, event registration, Link to \\
$f_{20}$ & Query function (transportation, weather, etc.) & WeChat in the city and county, \\
$f_{21}$ & Online poll (NPC deputies, "most beautiful" characters, etc.) & etc.) \\
$f_{22}$ & Online event registration (outdoor mountaineering, etc.) & Interaction (Collection channels of \\
$f_{23}$ & Link to WeChat in the city and county & public suggestions, Answer user's \\
\hline$f_{24}$ & Collection channels of public suggestions & questions easily in a timely manner, \\
$f_{25}$ & Answer user's questions in a timely manner & Timely and professional to solve \\
$f_{26}$ & Answer users' questions easily & problems, etc.) \\
$f_{27}$ & Timely and professional to solve problems & \\
\hline
\end{tabular}

\section{Classification of Service Quality Attributes of Government WeChat}

\subsection{Design of Analytical KANO Index of Government WeChat}

According to the research of X.Y. Gao, traditional KANO models have been added to quantitative measures [5]. The satisfaction scale of the positive/negative problem is shown in Table 2.

Table 2 Satisfaction scale for positive/negative problems

\begin{tabular}{lllllll}
\hline & & Like & Must-be & Neutral & Live with & Dislike \\
\hline $\begin{array}{l}\text { Attributes of service } \\
\text { quality }\end{array}$ & provide & 1 & 0.5 & 0 & -0.25 & -0.5 \\
\cline { 2 - 7 } & Not provided & -0.5 & -0.25 & 0 & 0.5 & 1 \\
\hline
\end{tabular}

If the attribute of the government WeChat is expressed as $F=\left\{f_{i} / i=1,2, \ldots, I\right\}, F$ is a collection of attributes of service quality, $f_{i}$ is the ith attribute of the service, $J$ is the total number of users surveyed. For each user $t_{i}=\left(\forall_{j}=1,2, \ldots, J\right)$, the evaluation of $f_{i}=\left(\forall_{i}=1,2, \ldots, I\right)$ is represented as 
$e_{i j}=\left(x_{i j}, y_{i j}\right)$,where, $x_{i j}$ is the score given to a attribute of service quality for the negative from problem, $y_{i j}$ is the score given to a attribute of service quality for the positive from problem. For each $f_{i}$, the average level of satisfaction for the negative form question is defined as $\bar{X}_{i}$, and the average level of satisfaction for the positive form question is defined as $\bar{Y}_{i}$,

$$
\begin{aligned}
& \bar{Y}_{i}=\frac{1}{J} \sum_{j=1}^{J} y_{i j} \\
& \bar{X}_{i}=\frac{1}{J} \sum_{j=1}^{J} x_{i j}
\end{aligned}
$$

From the perspective of users,the characteristics of an attribute of service quality can be represented as a vector, i.e., $f_{i} \sim \bar{r}_{l} \equiv\left(r_{i}, \alpha_{i}\right)$, where $\bar{r}_{l}$ is the magnitude of $\bar{r}_{l}$ and $\alpha_{i}$ is the angle between $\overline{r_{l}}$ and the horizontal axis.

$$
\begin{aligned}
\bar{r}_{l} & =\overrightarrow{\left|r_{l}\right|}=\sqrt{\bar{X}_{i}^{2}+\bar{Y}_{i}^{2}} \\
\alpha_{\mathrm{i}} & =\tan ^{-1}\left(\bar{Y}_{i} / \bar{X}_{i}\right)
\end{aligned}
$$

\subsection{KANO Classifiers for Attributes of User Demands in Shanxi}

Based on the formula (1) and formula (2), the KANO classifiers for attributes of user demands in Shanxi are shown in Table 3,and based on the formula (3) and formula (4), the statistical results of the questionnaire in Shanxi shown in Table 4. The attributes of service quality can be divided into four categories with the horizontal axis set at 0.73 and the vertical axis at 0.44 ,as shown in figure 1 .

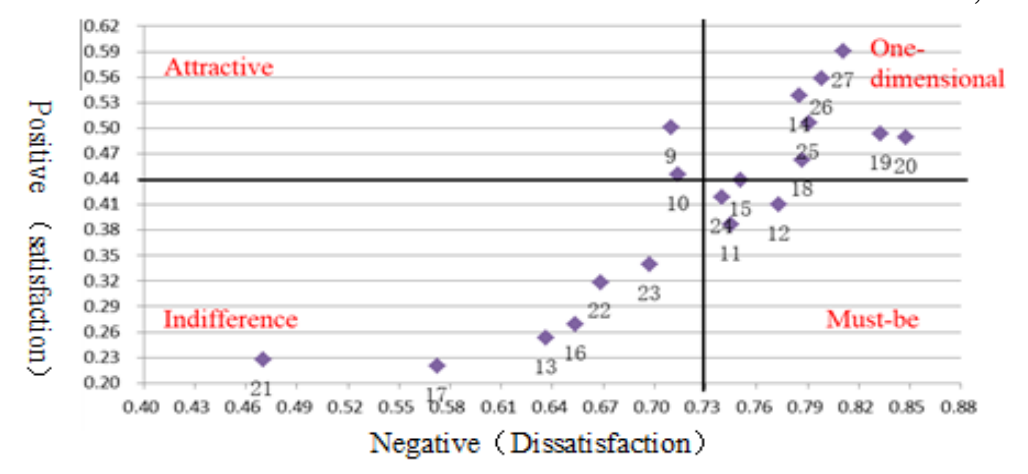

Fig. 1 KANO classifiers for attributes of user demands in Shanxi

According to figure 1, timely release of news and rich content of government affairs information are divided into the Attractive; the five attributes are divided into the Must-be, including humor of news language and local social news, etc.; the eight attributes are divided into the One-dimensional, including popular policy interpretation, etc.; the six attributes are divided into the Indifference, including sound news, news language with local characteristics, etc..

Similarly, it can be found that the service perception of government WeChat is different for different occupational groups in Shanxi Province: (1) Different professional groups in Shanxi believe that policy interpretation, online appointment to do things, online payments and inquiry functions belong to the One-dimensional, and number of news pushed each time, online poll belong to the Indifference. (2) For students, agencies and Institutions, privately or individually-owned business and others, various ways of information transmission is regarded as the Attractive. However, employees of the enterprises think that belongs to the Must-be, because they have great work pressure and have less time to read news, and want to get news information through audio and video. (3) For students, employees of the enterprises, agencies and Institutions and others, sound new and news language with local characteristics are regarded as the Indifference. But privately or individually-owned business think that regarded as the Attractive, which is innovative and can improve reading interest.

It can be seen from the above that different users have different demands for government WeChat based on their own demands characteristics. Different WeChat services should be provided 
in different industries for government WeChat for different users. The attributes that belong to the Attractive should be explored in practice to maximize their strengths; the attributes that belong to the Must-be should be upgraded and improved to meet the basic demands of users in Shanxi Province; the attributes that belong to the One-dimensional should continue to be maintained and the service level should be continuously improved; the attributes that belong to the Indifference can be ignored.

Table 3 Perceived evaluation of government WeChat by different occupational groups

\begin{tabular}{|c|c|c|c|c|c|c|c|c|c|c|c|c|}
\hline \multirow[t]{2}{*}{ Attributes } & \multicolumn{2}{|c|}{ Students } & \multicolumn{2}{|c|}{$\begin{array}{c}\text { privately or } \\
\text { individually-owned } \\
\text { business } \\
\end{array}$} & \multicolumn{2}{|c|}{$\begin{array}{l}\text { Agencies } \\
\text { and } \\
\text { Institutions }\end{array}$} & \multicolumn{2}{|c|}{$\begin{array}{l}\text { Employees } \\
\text { of the } \\
\text { enterprises }\end{array}$} & \multicolumn{2}{|c|}{ Others } & \multicolumn{2}{|c|}{ overall } \\
\hline & $\bar{X}_{i}$ & $\bar{Y}_{i}$ & $\bar{X}_{i}$ & $\bar{Y}_{i}$ & $\bar{X}_{i}$ & $\bar{Y}_{i}$ & $\bar{X}_{i}$ & $\bar{Y}_{i}$ & $\bar{X}_{i}$ & $\bar{Y}_{i}$ & $\bar{X}_{i}$ & $\bar{Y}_{i}$ \\
\hline$f_{9}$ & 0.48 & 0.65 & 0.19 & 0.88 & 0.44 & 0.84 & 0.65 & 0.59 & 0.27 & 0.81 & 0.71 & 0.50 \\
\hline$f_{10}$ & 0.46 & 0.69 & 0.19 & 0.88 & 0.37 & 0.86 & 0.62 & 0.56 & 0.21 & 0.81 & 0.71 & 0.45 \\
\hline$f_{11}$ & 0.37 & 0.68 & 0.10 & 0.92 & 0.28 & 0.91 & 0.59 & 0.57 & 0.19 & 0.84 & 0.75 & 0.39 \\
\hline$f_{12}$ & 0.40 & 0.75 & 0.10 & 0.92 & 0.31 & 0.93 & 0.61 & 0.62 & 0.18 & 0.90 & 0.77 & 0.41 \\
\hline$f_{13}$ & 0.22 & 0.62 & 0.06 & 0.88 & 0.16 & 0.83 & 0.42 & 0.38 & 0.08 & & 0.64 & 0.25 \\
\hline$f_{14}$ & 0.62 & 0.78 & 0.23 & & 0.50 & 0.93 & 0.64 & 0.66 & 0.24 & & 0.79 & 0.54 \\
\hline$f_{15}$ & 0.48 & 0.72 & 0.19 & & 0.35 & 0.91 & 0.61 & 0.5 & 0.22 & & 0.75 & 0.44 \\
\hline$f_{16}$ & 0.24 & 0.59 & 0.06 & 0.88 & 0.18 & 0.84 & 0.43 & 0.40 & 0.08 & 0.7 & 0.65 & 0.27 \\
\hline$f_{17}$ & 0.23 & 0.43 & 0.02 & 0.83 & 0.13 & 0.77 & 0.38 & 0.32 & -0.02 & 0.69 & 0.57 & 0.22 \\
\hline$f_{18}$ & 0.48 & 0.77 & 0.27 & 0.92 & 0.39 & 0.93 & 0.62 & 0.66 & 0.23 & 0.91 & 0.79 & 0.46 \\
\hline$f_{19}$ & 0.54 & 0.83 & 0.27 & 0.92 & 0.43 & 0.95 & 0.63 & 0.79 & 0.22 & 0.93 & 0.83 & 0.49 \\
\hline$f_{20}$ & 0.53 & 0.85 & 0.27 & 0.92 & 0.42 & 0.96 & 0.63 & 0.84 & 0.25 & 0.94 & 0.85 & 0.49 \\
\hline$f_{21}$ & 0.18 & 0.41 & 0.04 & 0.77 & 0.12 & 0.62 & 0.43 & 0.23 & 0.01 & 0.63 & 0.47 & 0.23 \\
\hline$f_{22}$ & 0.28 & 0.60 & 0.06 & 0.92 & 0.21 & 0.85 & 0.53 & 0.42 & 0.12 & 0.77 & 0.67 & 0.32 \\
\hline$f_{23}$ & 0.38 & 0.68 & 0.06 & 0.92 & 0.23 & 0.87 & 0.54 & 0.49 & 0.15 & 0.80 & 0.70 & 0.34 \\
\hline$f_{24}$ & .48 & 0.73 & 0.10 & 0.92 & 0.32 & 0.90 & 0.61 & 0.58 & 0.21 & 0.83 & 0.74 & 0.42 \\
\hline$f_{25}$ & 0.57 & 0.76 & 0.23 & 0.83 & 0.46 & 0.83 & 0.64 & 0.72 & 0.25 & 0.75 & 0.79 & 0.51 \\
\hline$f_{26}$ & 0.61 & 0.77 & 0.27 & 0.71 & 0.53 & 0.85 & 0.65 & 0.71 & 0.27 & 0.83 & 0.80 & 0.56 \\
\hline$f_{27}$ & 0.68 & 0.79 & 0.31 & 0.79 & 0.57 & 0.85 & 0.67 & 0.74 & 0.28 & 0.80 & 0.81 & 0.59 \\
\hline
\end{tabular}

Table 4 Calculation results of perceptions of different occupational groups in Shanxi Province

\begin{tabular}{|c|c|c|c|c|c|c|c|c|c|}
\hline \multirow[t]{2}{*}{ Attributes } & Students & $\begin{array}{c}\text { privately or } \\
\text { individually-owned } \\
\text { business }\end{array}$ & $\begin{array}{l}\text { Agencies } \\
\text { and } \\
\text { Institutions }\end{array}$ & $\begin{array}{l}\text { Employees } \\
\text { of the } \\
\text { enterprises }\end{array}$ & Others & overall & \multirow[t]{2}{*}{$\overline{\mathrm{r}_{1}}$} & \multirow[t]{2}{*}{$\alpha_{\mathrm{i}}$} & \multirow[t]{2}{*}{$\rho \mathrm{i}$} \\
\hline & 118 & 12 & 255 & 121 & 54 & 560 & & & \\
\hline$f_{9}$ & $\mathrm{M}$ & $\mathrm{A}$ & $\mathrm{M}$ & $\mathrm{M}$ & $\mathrm{O}$ & $\mathrm{O}$ & 0.87 & 35.21 & 0.66 \\
\hline$f_{10}$ & M & A & $\mathrm{O}$ & M & $\mathrm{O}$ & M & 0.84 & 31.97 & 0.65 \\
\hline$f_{11}$ & I & A & A & $\mathrm{M}$ & A & $\mathrm{M}$ & 0.84 & 27.42 & 0.67 \\
\hline$f_{12}$ & A & A & A & M & A & M & 0.88 & 27.92 & 0.70 \\
\hline$f_{13}$ & I & A & I & I & I & I & 0.68 & 21.65 & 0.57 \\
\hline$f_{14}$ & $\mathrm{O}$ & $\mathrm{O}$ & $\mathrm{O}$ & $\mathrm{O}$ & $\mathrm{O}$ & $\mathrm{O}$ & 0.95 & 34.41 & 0.73 \\
\hline$f_{15}$ & M & A & $\mathrm{O}$ & M & $\mathrm{O}$ & M & 0.87 & 30.30 & 0.68 \\
\hline$f_{16}$ & I & A & I & I & I & I & 0.71 & 22.35 & 0.58 \\
\hline$f_{17}$ & I & I & I & I & I & I & 0.61 & 21.00 & 0.51 \\
\hline$f_{18}$ & $\mathrm{O}$ & $\mathrm{O}$ & $\mathrm{O}$ & $\mathrm{O}$ & $\mathrm{O}$ & $\mathrm{O}$ & 0.91 & 30.44 & 0.72 \\
\hline$f_{19}$ & $\mathrm{O}$ & $\mathrm{O}$ & $\mathrm{O}$ & $\mathrm{O}$ & $\mathrm{O}$ & $\mathrm{O}$ & 0.97 & 30.63 & 0.76 \\
\hline$f_{20}$ & $\mathrm{O}$ & $\mathrm{O}$ & $\mathrm{O}$ & $\mathrm{O}$ & $\mathrm{O}$ & $\mathrm{O}$ & 0.98 & 29.99 & 0.77 \\
\hline$f_{21}$ & I & I & I & I & I & I & 0.52 & 25.80 & 0.42 \\
\hline$f_{22}$ & I & A & A & M & I & I & 0.74 & 25.50 & 0.60 \\
\hline$f_{23}$ & I & A & A & M & I & I & 0.78 & 25.95 & 0.63 \\
\hline$f_{24}$ & $\mathrm{M}$ & A & A & M & $\mathrm{O}$ & M & 0.85 & 29.51 & 0.66 \\
\hline$f_{25}$ & $\mathrm{O}$ & M & M & $\mathrm{O}$ & M & $\mathrm{O}$ & 0.94 & 32.63 & 0.72 \\
\hline$f_{26}$ & $\mathrm{O}$ & M & M & $\mathrm{O}$ & $\mathrm{O}$ & $\mathrm{O}$ & 0.97 & 34.98 & 0.74 \\
\hline$f_{27}$ & $\mathrm{O}$ & M & $\mathrm{O}$ & $\mathrm{O}$ & M & $\mathrm{O}$ & 1.00 & 36.04 & 0.76 \\
\hline
\end{tabular}




\section{Decision Analysis on Improving Service Quality of Government WeChat}

\subsection{The Path of Improving the Service Quality of Government WeChat in Shanxi}

The attributes of the service quality of government WeChat are divided into four quadrants with satisfaction and importance as two dimensions as shown in figure 2, where $\bar{r}$ is the average of the importance indicators for all attributes of the service quality, $\bar{\alpha}$ is the average of the satisfaction indicators. According to the importance and satisfaction in Table 5, the result of the service quality improvement decision-making for government WeChat in Shanxi is shown in Figure 2. The specific decision-making results are shown in Table 5.

Table 5 The result of the service quality improvement decision-making for government WeChat in Shanxi

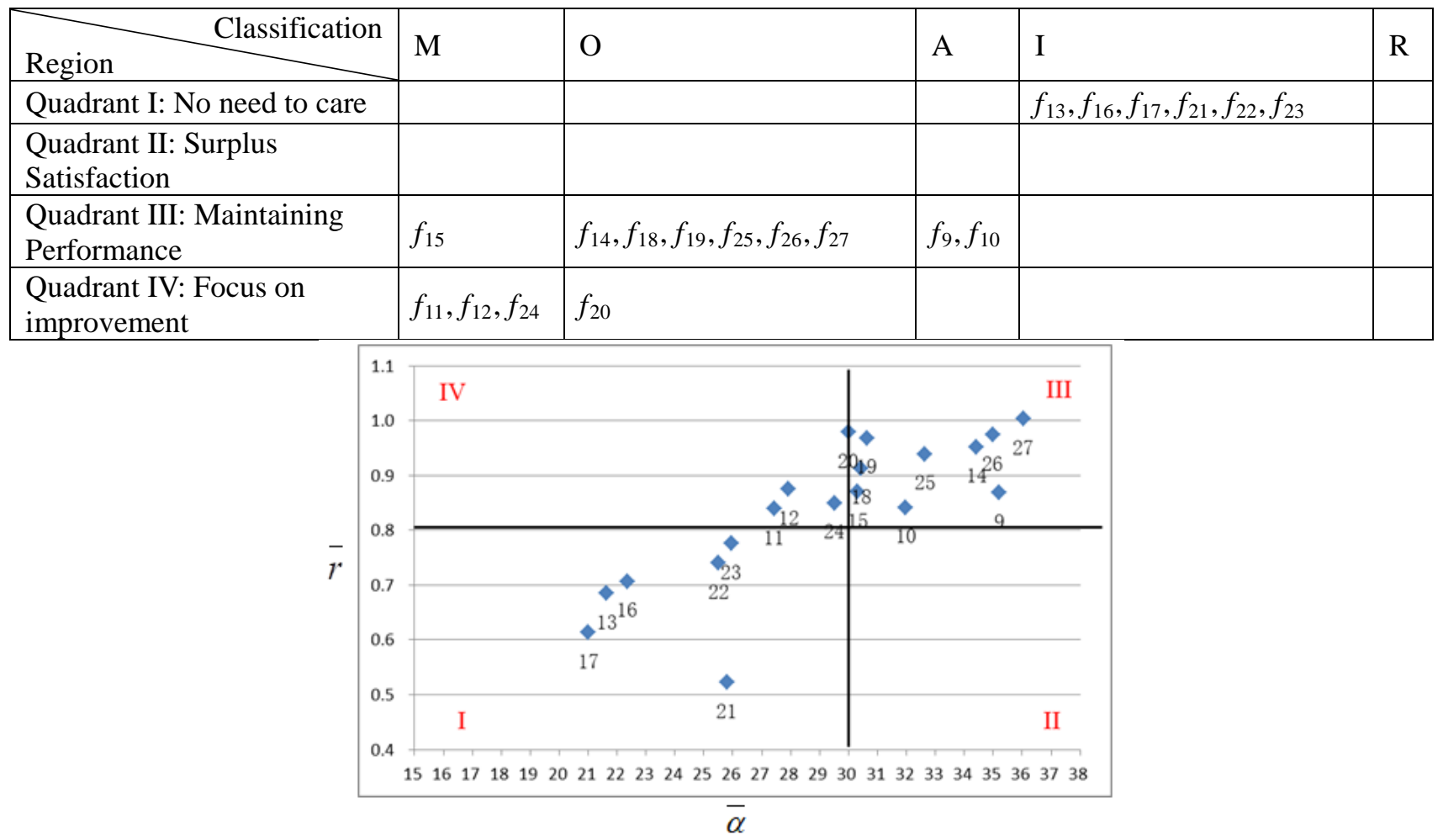

Fig. 2 The result of the service quality improvement decision-making for government WeChat in Shanxi

Quadrant I. No need to care: The user' perception about satisfaction and importance are not high for the attributes of service quality. $f_{13}, f_{16}, f_{17}, f_{21}, f_{22}, f_{23}$ are in the region, and both belong to the Indifference. So the government does not need to pay attention to these attributes.

Quadrant II. Surplus Satisfaction: The user perception about satisfaction is high, but perceived about importance is not high. No attributes are in this region, which is consistent with the current situation of government WeChat in Shanxi. Because of the late start of the government WeChat in Shanxi and the backwardness of technology, the demands of Shanxi users cannot be effectively met.

Quadrant III. Maintain performance: The user perception about satisfaction and importance are high. As can be seen from the results, $f_{9}, f_{10}, f_{14}, f_{15}, f_{18}, f_{19}, f_{25}, f_{26}, f_{27}$ are in the region. Most of these attributes are divided into the One-dimensional and only need to keep it.

Quadrant IV. Key enhancement: The user perception about satisfaction is not high, but perceived about importance is high. $f_{11}, f_{12}, f_{24}, f_{20}$ are in the region. Most of the attributes are divided into the Must-be, and government need to focus on improvement these attributes.

\subsection{The Configuration Index for Improving the Service Quality of Government WeChat in} Shanxi

$\mathrm{Q} \mathrm{Xu}$, et.al. Proposed the configuration index $\rho_{i}$ to enhance priority attributes that meet user 
expectations in the same region [3]:

$$
\rho_{i}=\frac{2 \sqrt{2}}{3}\left(1-\frac{\alpha_{i}}{\pi}\right) r_{i}
$$

Based on the formula (5), $f_{11}=0.67, f_{12}=0.70, f_{20}=0.77, f_{24}=0.66$, therefore, the priority of attribute enhancement is: $f_{20}>f_{12}>f_{11}>f_{24}$.

\subsection{Suggestions on the Service Quality of Government WeChat in Key Promotion}

According to the analysis results in the "Key enhancement" region, the author thinks that the service quality of government WeChat in Shanxi should be improved from the following aspects.

(1) Providing practical WeChat query function

From the perspective of users demand in Shanxi Province, Shanxi government WeChat should timely understand Shanxi users' expectations and provide practical query function to improve the usefulness of government WeChat to meet demands of information. It can improve the satisfaction and loyalty of users in Shanxi, and improve the service utilization to users in Shanxi for a long time.

(2) Providing a variety of ways to communicate information

The ways to communicate information of Shanxi Government WeChat is relatively simple, mostly composed of words and pictures, which makes the users more boring to reading information and reduces the interest of users on Shanxi government WeChat. Therefore, Shanxi government WeChat should not only use words, but also express it in the form of charts, videos, audio, animation and others, so as to increase the interest of users in Shanxi Province.

(3) Providing high quality content about government information

Local social news is an indispensable attribute of service quality, but the localized service quality of Shanxi Government WeChat is not high. The actual situation in Shanxi and the demand of users in Shanxi have not been closely integrated, and the regional characteristics have not been highlighted, so that the satisfaction of users in Shanxi Province is relatively low, and the stickiness and loyalty cannot be improved. Therefore, the characteristics of various regions of Shanxi Province should be integrated, and the subject of information content should be set up scientifically. Only in this way can only in this way can we enhance the value of government information and continuously improve the service capacity and quality of government WeChat services.

(4) Providing channels of interaction between the government and the public

The effective interaction between the government WeChat in Shanxi Province and the users in Shanxi Province is insufficient. Therefore, from the perspective of the demands of users in Shanxi Province, we should provide collection channels of public suggestions to listen to the practical difficulties and demands of users Shanxi Province. In this way, we can actively solve the problem of users in Shanxi, so as to narrow the distance between the government and the public.

\section{Acknowledgements}

This research was financially supported by Resource Based Economic Transformation Collaborative Innovation Center Special Fund, Shanxi Philosophy and Social Science Planning Project, Shanxi Graduate Education Innovation Project and Teaching Reform and Innovation Project at Shanxi University of Finance and Economics, they are respectively "Study and Enlightenment on Dynamic Capability of Hai Liang Group's Transformation" (ZX2018317) "Research on the evaluation and improvement of the service quality of Shanxi government WeChat” ([2017]2) "A study on the Cognition and Behavior of the Operators of Shanxi Tourism WeChat Public Account under the Background of Internet+" (2018SY071) and "Research-based teaching exploration and practice about Quality Management” (2018222).

\section{References}

[1] Information on http://www.cac.gov.cn/2018-01/31/c_1122347026.htm

[2] Information on http://www.xinhuanet.com/yuqing/2015/zwxmt/ 
[3] Q Xu, R.J. Jiao, M Helande, et al. An analytical KANO model for customer need analysis [J]. Design Studies, 2009, 30: 87-110.

[4] J. J Wang, H. Xing, Research on Influencing Factors of Internet Medical User Satisfaction Based on Kano Model [J]. Shanghai Pharmaceutical, 2018, 39 (17): 51-55.

[5] X.Y. Gao. The Research of Outdoor Fitness Facilities Design Based on Kano Model [A]. Advanced Science and Industry Research Center. Proceedings of 2017 2nd International Conference on Automation, Mechanical and Electrical Engineering (AMEE2017) [C].Advanced Science and Industry Research Center: Science and Engineering Research Center, 2017: 5. 